\title{
OS LIMITES DO CONTEXTO: A CONSTITUIÇÃO DA ESCRITA ESCOLAR EM OBJETO DOS ESTUDOS LINGUÍSTICOS
}

\author{
Émerson de Pietri \\ Universidade de São Paulo \\ São Paulo, São Paulo, Brasil
}

Resumo: No presente trabalho, apresentam-se resultados de investigação em que se observou o processo histórico de constituição da escrita escolar em objeto de pesquisas acadêmicas. Analisaram-se relatórios de pesquisas desenvolvidas em programas de pós-graduação nas três últimas décadas do século XX. Procurouse compreender o processo em questão enquanto constituição de um espaço discursivo específico. A investigação evidenciou o processo de redefinição dos modos como representado o contexto em que se elaboraria o texto escrito escolar. Com base no (re)posicionamento dos limites contextuais entre o intra e o extraescolar estabeleceramse e alteraram-se indices enunciativos para a referência de pessoa, tempo e espaço. As posições ocupadas pelos pesquisadores em relação a esses indices possibilitaram a apropriação de saberes para a constituição da escrita escolar em objeto de discurso.

Palavras-chave: Interdiscurso. Pesquisa Acadêmica. Escrita Escolar.

1 INTRODUÇÃO

Nas décadas finais do século XX, no Brasil, houve um importante processo de reordenação discursiva, em que o estabelecimento de novas estratégias e a configuração de novos conceitos possibilitaram a

\footnotetext{
* O presente trabalho foi elaborado a partir do relatório resultante de pesquisa financiada pelo CNPq (Processo n.: 400540/2008-8).

Docente da Faculdade de Educação da USP. Doutor em Linguística Aplicada ao Ensino de Língua Materna pela Universidade Estadual de Campinas (UNICAMP). Email: pietri@usp.br
} 
constituição de objetos e a ampliação, pela complexificação de suas relações interdiscursivas, dos campos do acadêmico, do pedagógico e do oficial, no que se refere à temática da língua portuguesa e de seu ensino.

No campo do oficial, durante o regime militar operaram-se mudanças na legislação educacional que reordenaram o currículo do ensino básico, tanto em sua extensão quanto em sua estrutura. A Lei n. 5.692/71 determinava que a escolaridade mínima obrigatória a ser oferecida pelo Estado se ampliasse, dos quatro anos do então denominado ensino primário, para os oito anos da educação básica, que se dividiria então em ensino primário ( $1^{\mathrm{a}}$ a $4^{\mathrm{a}}$ séries $)$ e ensino ginasial $\left(5^{\mathrm{a}}\right.$ a $8^{\mathrm{a}}$ séries $)$. Essa ampliação do percurso escolar se fez acompanhada do estabelecimento de uma estruturação curricular que se organizava em torno de matérias, as quais circunscreviam, então, as disciplinas específicas (cf.: SILVA; ARELARO, 1985).

Assim, a Resolução CFE n. 8/71 associou à matéria de Estudos Sociais as disciplinas Geografia, História e Organização Social e Política do Brasil; a matéria de Ciências incluiria Matemática, Ciências Físicas e Biológicas. Língua portuguesa, disciplina que interessa mais diretamente à presente discussão, se encontrava localizada no interior da matéria de Comunicação e Expressão, juntamente com as disciplinas de Educação Artística e Educação Física. Essa organização curricular foi compreendida de modos diversos, tanto no campo do pedagógico, quanto no campo do acadêmico (cf.: PIETRI, 2010). Esses modos diferentes de compreensão se observam, por exemplo, nas denominações que se fizeram correntes para livros didáticos de português, que passaram a apresentar em seus títulos, a partir do período em foco, a referência à matéria de Comunicação $e$ Expressão.

Essa associação direta entre matéria e disciplina é observada também nas considerações de Soares (2002) quanto às alterações que o português enquanto unidade curricular teria apresentado no momento histórico em questão. Segundo a autora, a disciplina de língua portuguesa teria sido reconfigurada em seus objetivos e conteúdos de modo a responder à submissão do currículo escolar ao projeto desenvolvimentista da ditadura militar. Nesse período de pragmatismo econômico, haveria um hiato no 
ensino de português quanto ao modo como ele se estruturou em suas características apontadas como tradicionais (i.e., centrado no ensino de gramática e referenciado na escrita dos grandes escritores da literatura, exemplar do bom uso do idioma): a comunicação, baseada em modalidades outras que não apenas a verbal escrita, assumiria, segundo um princípio de instrumentalidade, lugar de destaque num ensino voltado para o preparo de mão de obra para o mercado de trabalho.

No mesmo momento em que se desenvolve o processo de reconfiguração do objeto de ensino, em função dos modos como estabelecidas então as relações entre os discursos oficial e pedagógico, no discurso acadêmico se processa a reconfiguração do objeto dos estudos linguísticos (cf.: PIETRI, 2007a). Nos números 16 e 23 dos Cadernos de Pesquisa da Fundação Carlos Chagas, são publicados os primeiros estudos brasileiros (VIANNA, 1976) a respeito da redação escolar. Responsáveis pela elaboração, aplicação e avaliação de provas de vestibular, a Fundação Carlos Chagas convida um grupo de pesquisadores linguistas para analisar as redações produzidas pelos candidatos por ocasião dos exames.

Com o objetivo de produzir subsídios que auxiliassem na compreensão dos fatores que condicionavam a produção textual e que definiam as características dos textos produzidos, os autores se fundamentaram, inicialmente, em elementos teóricos dos estudos linguísticos para o tratamento dos problemas de pesquisa. Porém, no momento da análise dos dados, recorreram a saberes próprios à tradição gramatical e à retórica, dado que, como explicitado nesses estudos, as bases teóricas da Linguística não ofereciam subsídios adequados para o tratamento do texto escrito, mas, sim, de seu objeto primeiro - a língua em sua relação dicotômica com a fala.

Trata-se, portanto, de um momento de reordenação discursiva, em que se reconfigura o objeto dos estudos linguísticos. A escrita, cuja interdição representou um movimento necessário para a circunscrição saussuriana de um campo próprio à Linguística, passa a figurar então como um objeto legítimo dessa ciência. A reconfiguração do objeto e a diversificação do leque de materiais considerados legítimos para a análise linguística promovem, assim, uma ampliação desse campo de estudos, cuja 
produtividade em novas bases se apresenta também, já a partir dos anos finais da década de 70, em pesquisas de mestrado e de doutorado que têm a escrita escolar como objeto de investigação. Os relatórios resultantes dessas pesquisas, produzidas no período compreendido entre 1976 e 1996', compõem o material de análise do presente trabalho.

A investigação se orientou pela seguinte pergunta: de que modo o trabalho com os índices enunciativos - de pessoa, de tempo e de espaço possibilitaram a constituição da escrita escolar em objeto de pesquisa em investigações acadêmicas?

A análise mostrou que a constituição da escrita escolar em objeto de discurso se realizou com base no processo de redefinição dos modos como concebido o contexto em que se elaboraria o texto escrito na escola. A redefinição das dimensões atribuídas a esse contexto, ao longo do momento histórico observado, se fez no sentido de circunscrever cada vez mais especificamente o espaço escolar. Da sociedade de comunicação de massas, à comunidade em que inserida a escola, para, por fim, o tratamento do espaço intraescolar ele mesmo, a partir de um lugar externo de observação (localizado na academia), no movimento dos limites contextuais estabeleceram-se e alteraram-se índices enunciativos para a referência de pessoa, tempo e espaço. A hipótese com que se trabalha é a de que as posições ocupadas pelos pesquisadores em relação a esses índices possibilitaram a reconfiguração de estratégias, de conceitos e de modalidades enunciativas para a constituição da escrita escolar em objeto dos estudos linguísticos.

\section{REFERENCIAL TEÓRICO E METODOLÓGICO}

Segundo Maingueneau (1997, p. 116), o universo discursivo corresponderia ao "conjunto de formações discursivas de todos os tipos que coexistem, ou melhor, interagem, em uma conjuntura". Seria um conjunto finito, mas irrepresentável em sua totalidade, tendo função metodológica enquanto noção em que se recortam os campos discursivos. Campo

\footnotetext{
${ }^{1}$ As referências para o estabelecimento desse recorte temporal serão apresentadas a seguir, quando do tratamento da constituição do corpus.
} 
discursivo é definido como "um conjunto de formações discursivas que se encontram em relação de concorrência, em sentido amplo, e se delimitam, pois, por uma posição enunciativa em uma dada região". Já o espaço discursivo seria o resultado da delimitação de "um subconjunto do campo discursivo, ligando pelo menos duas formações discursivas que, supõe-se, mantêm relações privilegiadas, cruciais para a compreensão dos discursos considerados" (1997, p. 117).

O percurso histórico apresentado mais acima parece evidenciar a possibilidade de delimitar, no campo discursivo em que se tematiza o ensino de língua portuguesa, um espaço discursivo constituído com base nas relações que se estabeleceram entre os discursos oficial, pedagógico e acadêmico. Esse processo interdiscursivo se realizaria, assim, na interface entre o acadêmico e o escolar, relacionando de modos diversos diferentes posições e funções atribuídas a um e outro desses dois lugares.

Segundo Maingueneau (1997), os limites entre um e outro discurso se definem pela polêmica que se instaura com a contraposição de semas valorados positiva ou negativamente nas bases semânticas de cada um dos discursos que participam do processo interdiscursivo, um processo que envolve negações, denegações e partilhas entre os concorrentes. Considerados dessa maneira, os discursos "nascem" de um trabalho sobre outros discursos, através de um processo contínuo de delimitação recíproca, fundamentado num mecanismo de interincompreensão. O discurso do Outro é compreendido, portanto, segundo as categorias do discurso tradutor (o discurso agente). A relação com o Outro é possível, então, apenas a partir do simulacro que dele é construído.

A precedência do interdiscurso sobre o discurso se caracteriza, assim, pela interincompreensão regrada: um sistema de regras define a especificidade de uma enunciação com base numa coerência global, que, segundo Maingueneau (2005, p. 22), "restringe simultaneamente o conjunto dos "planos" discursivos: tanto o vocabulário quanto os temas tratados, a intertextualidade ou as instâncias de enunciação...”.

Partindo-se então da hipótese de que a determinados discursos correspondem estruturações textuais específicas, isto é, que os gêneros textuais estão em concordância com a semântica de uma dada formação 
discursiva (cf.: MAINGUENEAU, 2005), é possível considerar que a enunciação opera em dois níveis (ou duas ordens) simultaneamente: interdiscursivamente, delimita o discurso em relação ao que seja sua exterioridade; intradiscursivamente, define o espaço e o tempo do dizer.

Os dados analisados no presente trabalho se produzem segundo esse mecanismo enunciativo: considera-se que num dado momento histórico, determinados índices discursivos sejam comuns a uma determinada formação discursiva. A referência constituída com base nesses índices garante a definição de um espaço e de um tempo para os dizeres, e, com isso, a possibilidade de movimento dos sujeitos para a produção dos objetos de discurso.

A investigação sobre os modos de estruturação textual permitiria observar quais deslocamentos se operam nos processos de delimitação recíproca entre os discursos que constituem o campo discursivo em questão, e de que modo se delimitou o espaço discursivo definido pelos interesses específicos da análise desenvolvida. O trabalho com os dados na presente investigação consiste em caracterizar, nos documentos analisados, quais os recortes teóricos operados, pelos seus autores, no momento de delimitar um espaço de trocas entre discursos, e a possibilidade, assim, de constituição de objetos de discurso (nesse caso, a escrita escolar).

Nesse sentido, é necessário que se considere a questão da enunciação não somente em relação a sua genealogia, mas aos modos como é atualizada num dado espaço discursivo (de acordo com a terminologia proposta por Maingueneau (1997)), em que não necessariamente se opera sobre os limites de formações discursivas concorrentes, mas se divisam loci de atuação dos sujeitos. Essa perspectiva se torna mais interessante quando o objetivo é o de observar, por exemplo, o trabalho realizado por pesquisadores ao definir os limites de duas investigações (e, assim, os processos de referenciação que sustentam a possibilidade do dizer — dentre eles, a posição atribuída aos sujeitos).

O corpus de análise é composto por documentos representativos do discurso acadêmico sobre escrita escolar e se constitui de teses e dissertações publicadas entre 1976 e 1996: o limite inicial do recorte corresponde ao momento de publicação dos Guias Curriculares (SÃO 
PAULO, 1975); seu limite final se relaciona ao fato de novos documentos oficiais serem publicados no ano de 1997 (no caso, os Parâmetros Curriculares Nacionais (BRASIL, 1997; 1998)), o que inaugura uma nova ordem discursiva sobre ensino de língua portuguesa no país, exigindo investigação que se coloca fora das possibilidades do presente trabalho. Entre um limite e outro, publica-se a Proposta Curricular para o Ensino de Língua Portuguesa $-1^{\circ}$ grau (SÃO PAULO, 1987). No período observado - entre os anos de 1976 e 1996 - algumas características próprias a momentos específicos de conjunção dos discursos acadêmico, pedagógico e oficial puderam ser então evidenciadas, diferenciando-se, assim, três modos de constituição das relações interdiscursivas em jogo, denominadas, um tanto arbitrariamente, com a referência ao momento histórico (décadas de 70, 80 e 90) em que um desses modos prevaleceu.

A opção metodológica de considerar para o corpus apenas as produções acadêmicas paulistas se fez em razão da tentativa de compor um conjunto mais coeso e coerente, consideradas as relações interdiscursivas que se produziram nesse lugar, as quais se projetaram em ações, por parte do Estado, como a elaboração de Guias e Propostas Curriculares e a oferta de cursos de formação continuada a professores da rede pública. Seria possível caracterizar de modo mais fundamentado dialogicamente as condições de produção em que se desenvolveram então os processos interdiscursivos em análise, consideradas as articulações entre diferentes instâncias institucionais.

\section{RESULTADOS}

Como referido, o trabalho com os dados na presente investigação consistiu em observar, nos relatos de pesquisa analisados, quais estratégias possibilitaram a operação de recortes teóricos, pelos seus autores, no momento de delimitar um espaço de trocas entre discursos, e a possibilidade, assim, de constituição de objetos de análise. O objetivo foi o de localizar as diferentes posições em relação às quais foram estabelecidos os limites entre o contexto escolar e o extraescolar, em momentos históricos distintos, e de que modo os sujeitos pesquisadores se 
movimentaram, entre um e outro dos espaços constituídos por essas diferentes delimitações, em seu trabalho para a configuração de temas, conceitos e modalidades enunciativas, considerando-se o processo de constituição da escrita em objeto de pesquisa.

\subsection{A DÉCADA DE 70: A ESCOLA E A SOCIEDADE DE MASSAS}

Dentre os documentos que compõem o corpus relativo à década de 70, encontram-se dissertações e teses defendidas entre os anos de 1976 e 1981. Considerou-se que as investigações publicadas já nos anos iniciais da década de 80 filiam-se às condições de produção próprias à década anterior, momento de emergência do processo de constituição da escrita escolar em objeto de pesquisa, não apenas por se desenvolverem, de fato, nos anos finais da década de 70, mas por compartilharem características discursivas próprias às produções desse momento. $\mathrm{O}$ fato de o texto escrito escolar se constituir em acesso às condições de sua produção parece ser o fator decisivo para definir a localização histórica dessas pesquisas.

A produção acadêmica sobre escrita escolar, no período em análise, se caracterizou por formular um problema (no caso, o fato de que a escrita escolar se encontraria em crise); procurar suas causas (a indústria cultural e a sociedade de massas estariam na origem do problema); e agenciar elementos teóricos, de campos distintos, que pudessem oferecer subsídios para o tratamento da questão em torno do objeto central, a escrita escolar.

As teorias explicativas agenciadas nas pesquisas então desenvolvidas são fundamentadas, num plano principal, em recursos teóricos da psicologia (para se considerar o sujeito), e dos estudos sociológicos e culturais (para se pensar sobre as condições mais amplas em que estariam inseridos a escola e o aluno). Em apoio a essa fundamentação teórica, como instrumental para analisar os dados, são utilizados recursos dos estudos da linguagem, principalmente em suas vertentes estruturalista e semiótica, a que se associam elementos da perspectiva funcional (MOYSÉS, 1976); da teoria da informação e dos estudos culturais e sociológicos (DIAS, 1977); da semântica (HILGERT, 1978); dos estudos literários (MESERANI, 1980); da linguística textual e da linguística da enunciação (ROCCO, 1981). 
O agenciamento de perspectivas teóricas diversas para a produção de dados e análise, nas teses e dissertações observadas, se fez de modo a compatibilizar epistemologicamente concepções de sujeito e de referência apropriadas de campos nem sempre assimiláveis entre si. A hipótese com que se trabalha é a de que a ambivalência do objeto de estudo, antes que um problema, foi o fator que possibilitou que o processo discursivo em questão pudesse se caracterizar pela coerência — a referência a escrita escolar permitiu que se fizesse um movimento entre o texto escrito (a redação) e o contexto de sua produção (a escola inserida nas condições sociais mais amplas): no espaço construído entre esses dois pontos de ancoragem, o pesquisador se movimentou, aproximando e alternando concepções de sujeito (de base psicológica ou de base social, por exemplo), as quais possibilitaram aproximar diferentes discursos e perspectivas teóricas diversas - o que se evidencia nas associações de cognição e inconsciente; indivíduo e sociedade; semiótica e psicanálise; psicologia e linguística; gramática e ideologia; etc.

Em relação ao contexto, as causas são percebidas segundo estejam no interior ou no exterior da escola. Na escola, os problemas encontrados se vinculariam às condições históricas de produção do texto escolar (e a passividade do sujeito frente a essas condições), e às características tradicionalistas e normativas da escola. As causas externas à escola são associadas à sociedade de massas, à indústria cultural e à função social, política e ideológica da escola numa sociedade de classes.

Um elemento comum aos trabalhos que tomaram a escrita escolar em objeto de análise, no período estudado, é a consideração de que os problemas encontrados nessas produções se constituiriam então em sintomas de uma situação geral sobre as condições do ensino e da aprendizagem nas escolas brasileiras. O apontamento de uma crise na linguagem está presente nos trabalhos observados não apenas para caracterização dos textos que compõem seu material de análise, a redação escolar, mas parece funcionar como elemento discursivo, um índice, que possibilita o trabalho mesmo de investigação: diagnosticada a crise, observados os sintomas, tornava-se necessário buscar subsídios teóricos e realizar o trabalho de produção e análise de dados que levassem ao conhecimento das causas de tal estado de coisas. 
Como exemplo do processo em análise, apresentam-se alguns elementos da pesquisa de Rocco (1981). A autora afirma que a reprodução do senso comum (materializados em clichês e frases feitas) em textos escritos escolares seria indício da existência de uma suposta crise na linguagem, que estaria relacionada ao nível de estruturação mental dos sujeitos que produziam textos na escola. A essa hipótese, a autora agrega ainda uma decorrente, que considera a possibilidade de relacionar condições internas aos textos, a condições externas, relacionadas ao "ambiente escolar, social, cultural, econômico a que pertencem os indivíduos examinados" (p. 3).

No que se refere às premissas de base psicológica do trabalho, sustenta-se que a estruturação do pensamento dos candidatos ao vestibular deveria se encontrar no nível formal, segundo critérios piagetianos. O que teria sido encontrado, no entanto, foram usos característicos de estruturação do pensamento própria à infância, "um nível de raciocínio inferior àquele pertinente à idade" (p. 95).

As causas de tais resultados estariam na escola, na família e no sistema educacional, mas também no "bombardeio excessivo dos veículos de comunicação de massa" (p. 89). Em sua conclusão, a autora reafirma a hipótese de as causas de tal situação serem a padronização estabelecida pela sociedade de massa, pela oferta de objetos prontos para usar, que não demandariam do sujeito nenhum tipo de trabalho criativo ou imaginativo. A solução seria alterar as relações dos sujeitos com essas condições que se lhes apresentam, o que, se não pudesse ser feito pela família e pela escola, dadas suas características naquele determinado momento histórico, seria atribuição da Universidade, que poderia oferecer formação diferenciada a seus alunos, que, por sua vez, a multiplicariam.

No trabalho de Rocco (1981) encontram-se referências a elementos da linguística textual, e, com base neles, a consideração das redações escolares como objeto a ser analisado segundo categorias produzidas para o texto concebido como unidade distinta da palavra e da frase. Porém, a análise dos textos se faz de modo a possibilitar a investigação das condições de produção dos textos escritos em contexto de ensino. A aproximação de perspectivas teóricas diversas garantiria as bases dessa 
investigação. A interdisciplinaridade possibilitaria observar as relações entre produção escrita e desenvolvimento psicológico dos vestibulandos ao agenciar concepções piagetianas, que ofereceriam as bases para as hipóteses de pesquisa, e, também, contribuições de estudos de outras áreas do conhecimento, sobretudo dos estudos da linguagem, de modo a que não fosse necessário realizar análises estritamente linguísticas do material, mas que se usassem "seus conceitos e descobertas" (p. 6).

Assim, ainda que elementos de linguística textual fundamentem o trabalho de análise dos textos, a noção de referência que embasa as considerações sobre a relação do sujeito com a produção linguística se faz segundo a perspectiva construtivista, e, nesse sentido, não se confere ao texto autonomia enquanto objeto de análise. A dependência epistemológica do texto em relação a explicações de base psicológica evidencia a tentativa de lidar com um espaço existente, então, entre concepções de linguagem e de conhecimento fundadas em noções de referência de base semiológica, e concepções fundadas em noções de referenciação de base textual.

A posição tensa, no lugar das fronteiras discursivas, ocupada pelo sujeito (em suas diversas concepções), parece ser o fator que possibilita o encontro de dois ou mais campos de saber, e a aproximação, promovida em função dos objetivos das investigações, de concepções de referência distintas. Assim, a coexistência de diferentes posições atribuídas ao sujeito possibilitaria o processo de aproximação dos discursos e de sua colocação em situação de delimitação recíproca (cf. MAINGUENEAU, 2005), promovendo a constituição da polêmica necessária para a produção discursiva.

\subsection{A DÉCADA DE 80: DA COMUNIDADE PARA A ESCOLA}

Nos trabalhos de pesquisa desenvolvidos no período referente à década de 80 , os fatores extratextuais são também considerados para o tratamento dos dados e sua análise. Porém, diferentemente das pesquisas sobre escrita escolar desenvolvidas nos anos finais da década de 70, os fatores externos não são percebidos como causas dos problemas de redação, mas como condicionantes da produção do texto, constituindo-se, 
assim, em elementos que fundamentariam a organização textual. O texto é considerado neste momento já como uma unidade, em consonância com perspectivas teóricas dos estudos do texto e com propostas de ensino de língua portuguesa elaboradas então.

A organização textual do escrito produzido em contexto de ensino é considerada, nas dissertações e teses observadas, em função de condicionantes linguísticas e/ou sociais, associadas mais ou menos explicitamente a questões próprias aos estudos em sociolinguística. No momento histórico em observação, as diferenças entre as modalidades referenciam as delimitações que se estabelecem com base em características sociais, econômicas e linguísticas, as quais se interrelacionam segundo modos diversos nos trabalhos observados. Os problemas apontados para a escrita escolar são considerados em relação a fatores internos e externos ao processo de escolarização, num movimento em que se associam, aos primeiros, os fatos de oralidade, e aos segundos, os elementos da escrita.

Oralidade e escrita são associados então a diferentes espaços e tempos - a oralidade, ao tempo e ao espaço extraescolar; a escrita, ao tempo e ao espaço intraescolar -, ocupados de modos distintos pelos sujeitos em seu trabalho para a construção de objetos de discurso.

Nos trabalhos produzidos no período, considera-se a relação entre oralidade e escrita em associação com as transformações que a escola poderia promover nas possibilidades de usos de linguagem dos sujeitos. A escola (ou a escolarização) teria a função discursiva de constituir referência para a tematização de diferenças sociais, econômicas e linguísticas, diferenças que se evidenciariam pela função catalisadora que a escola possuiria ao representar a coesão institucional face à diversidade social.

A instituição escolar é então considerada seu em interior. O pesquisador não se coloca como um observador externo, mas como um agente que atua em busca de transformações no contexto de ensino. Nota-se um deslocamento dos pesquisadores no sentido de se aproximar do contexto escolar. Nesse deslocamento, que tem como referência os índices estabelecidos pela oposição entre o extra e o intraescolar, o movimento de aproximação à escola se realiza em paralelo com a aproximação entre 
pesquisador e professor, que atinge seu ápice no momento em que a pesquisa se volta para a observação de alterações promovidas nas condições de ensino pela própria atuação do pesquisador-professor.

O tratamento da escrita escolar como material de análise permitiu que, num sentido, o pesquisador se movimentasse entre referenciais teóricos determinados e deles se apropriasse para o tratamento da questão considerada: encontram-se nos fundamentos teóricos das pesquisas observadas elementos da Linguística Textual, associados a noções vindas da sociolinguística e a considerações quanto a aspectos lexicais (ALMEIDA, 1980), ou a questões relativas aos problemas da narrativa (BASTOS, 1984); conceitos da sociolinguística associados a saberes gramaticais tradicionais (BASTOS, 1986); conceitos da análise do discurso de linha francesa (GALLO, 1989); elementos de linguística textual, associados a elementos produzidos em estudos sobre as diferenças entre o oral e o escrito, a problemas de argumentação, e a produções sobre o narrativo (SATO, 1989).

Num outro sentido, o tratamento da escrita escolar permitiu que as diferenças entre modalidades fossem associadas a diferenças entre as condições intra e extraescolares, ocupando posições diversas, entre esses dois índices, segundo se movimentasse para considerar essas condições de um ou de outro ponto de vista. Esse movimento possibilitou, então, a apropriação de elementos teóricos para o tratamento da própria delimitação desses espaços e da caracterização de suas condições.

A tematização das relações da escola com seu exterior possibilitou, desse modo, a constituição da escrita escolar em objeto de pesquisa ao produzir um dispositivo que sustentasse o movimento analítico. $\mathrm{O}$ percurso se referenciou em índices associados a elementos que compuseram pares opositivos associados: /oralidade x escrita/, relacionado ao par/diferença linguística x norma linguística/, se associava a outro par opositivo, baseado na contraposição /condições de produção intraescolares x condições de produção extraescolares/.

Para ilustrar o processo em questão, apresentam-se elementos do trabalho de Sato (1989). O objetivo do trabalho da autora é o de analisar um projeto de ensino, realizado durante um semestre em um curso noturno de 
$2^{\circ}$ grau de escola pública, no $2^{\circ}$ ano colegial (p. 11). A prática pedagógica é o objeto de seu trabalho de análise, cujo objetivo seria o de encontrar marcas linguísticas nos textos dos alunos que evidenciassem reflexos do trabalho pedagógico desenvolvido ao longo de um semestre (p. 12). Dadas as dificuldades que seriam advindas do "desconhecimento das especificidades dos códigos oral e escrito", realizou-se em sala de aula uma sequência de atividades com o objetivo de promover o desenvolvimento dos conhecimentos relativos a elementos próprios à escrita, tais como "a organização do texto em parágrafos e emprego de sinais de pontuação", ou a "utilização lexical precisa e pertinente ao contexto e emprego coerente de relatores interfrásticos e discursivos" (p. 13).

Em seu trabalho, a relação entre normatização e diferenças entre modalidades é tratada considerando-se que os problemas na modalidade escrita, encontrados nos textos produzidos pelos alunos, seriam decorrentes da transposição, para o escrito, de elementos próprios à modalidade oral. Tematiza-se, então, a relação entre norma culta e ensino, afirmando Sato (1989) que um dos princípios que norteou sua atuação em sala de aula, durante o desenvolvimento da pesquisa, foi a "relativização da norma culta, de forma a alterar a concepção de língua perpetuada pela escola" (p. 13).

A relação oralidade-escrita, um dos pontos de vista privilegiados pela investigação, teria assumido destaque, colocando-se no centro das discussões. Os trabalhos de análise se voltariam, então, para a procura de marcas de oralidade nos textos escritos dos alunos, consideradas as questões sobre variação linguística, registro e normatização. Os problemas de escrita seriam decorrentes, por exemplo, da transposição para a escrita da "espontaneidade característica da conversação" (p. 73), ou pela "oscilação entre registro formal e informal, que pode ser entendida como alternância entre oral e escrito" (p. 88).

A proposta da pesquisadora é a de conhecer os recursos da oralidade como forma de rever as bases do ensino tradicional e seus resultados para a aprendizagem da escrita, uma vez que possibilitaria tratar de questões relativas a dados socioculturais e situacionais, além de diferenciar o trabalho com as modalidades, considerando os princípios de planejamento e editoração próprios à escrita, além de seu caráter de permanência. 
A análise do corpus se direcionou para a relação oralidade-escrita e para o texto produzido em contexto de sala de aula. A fundamentação teórica se fez com referência a elementos de linguística textual, com base em Halliday e Hasan (1973), e em discussões que propusessem novos modos de perceber os conceitos de coesão e coerência. A discussão sobre as noções de coesão e coerência se fez com base em discussões sobre as diferenças entre o oral e o escrito (MARCUSCHI, 1986; KATO, 1986), e nas características próprias aos gêneros desenvolvidos em sala de aula, considerando-se então questões próprias à argumentação $(\mathrm{KOCH}, 1987$; ORLANDI, 1987) e ao narrativo (LABOV; WALETSKY, 1967).

Percebe-se, no trabalho de Sato (1989), que o texto parece ser considerado autonomamente, enquanto objeto de análise, não mais se caracterizando apenas como produto das condições de produção, mas parte delas. Nos dizeres da autora, "uma das pretensões [do] estudo é a de abordar analiticamente textos de alunos enquanto uma totalidade discursiva, sem abrir mão de unidades linguísticas menores evidentemente" (p. 43).

O movimento operado pela pesquisadora se faz no sentido de colocar-se em situação de equivalência em relação à professora. A pesquisa não se faria, assim, de modo a compreender, a partir de uma exterioridade, o que aconteceria no contexto observado: nesse momento, parece se operar a tentativa de produzir um diálogo próximo entre posições teóricas e prática de sala de aula.

A posição ocupada pela pesquisadora, nesse momento, se encontra no interior da escola, percebida como elemento constitutivo do social, e, portanto, situada política e historicamente. O texto escrito produzido em contexto escolar guardaria em si as marcas dessa historicidade, que trariam em sua memória também os traços próprios à instituição em que se produziram. A escola é vista não mais em contraposição a um espaço não escolar, espaços que se delimitariam pela contraposição das positividades das condições de produção não escolares às negatividades das condições escolares.

Assim, o movimento realizado pelo pesquisador, em sua aproximação das condições escolares de produção do texto, tendo como 
referência os índices de tempo e espaço estabelecidos pelas oposições entre oralidade e escrita (e a associação dessas modalidades com o contexto extra e intraescolar, em torno do processo de escolarização), possibilitou a constituição da escrita escolar em objeto de discurso em função da apropriação de saberes sobre língua e texto elaborados pelos estudos linguísticos.

A hipótese com que se trabalha é a de que a escrita escolar se constitui em objeto de discurso em função da ambivalência das posições ocupadas pelo sujeito da investigação: no movimento entre uma posição e outra, a voz do sujeito da investigação, na condição de professor, constrói as referências desse objeto para seu interlocutor, o sujeito da investigação na condição de pesquisador.

\subsection{A DÉCADA DE 90: A ACADEMIA E A ESCOLA}

As considerações sobre a escrita escolar que se realizam na primeira metade da década de 90 do século XX se fazem em resposta a questões que seriam apresentadas pelas condições do ensino em contexto escolar. Os problemas encontrados na escrita escolar seriam decorrentes dos modos de produção do texto na escola, e não de fatores próprios à sociedade mais ampla, como se apontava na década de 70, por exemplo, em que se associavam os problemas apontados para a escrita como resultantes da influência dos meios de comunicação de massa e da indústria cultural sobre os sujeitos, com os reflexos que teriam na escola.

No mesmo sentido, a relação entre elementos intra e extraescolares, importante fator para as considerações sobre escrita escolar na década de 80, perde valor nesse momento histórico: os trabalhos se voltam para a aplicação de uma perspectiva teórica específica para o tratamento do texto em sala de aula - diferentemente do que acontecia anteriormente, quando uma perspectiva teórica era acionada para promover mudanças nas condições de produção do texto em sala de aula (centradas na escrita), de modo a aproximá-las das condições de produção do texto em seu exterior (centradas na oralidade). 
Os fatores extraescolares acima mencionados, quando referidos em trabalhos produzidos no período histórico aqui observado, têm como fonte os resultados das investigações realizadas nas décadas anteriores. Há, assim, na década de 90, um conjunto de saberes acadêmicos sobre escrita escolar que compõe já uma memória: trata-se, então, não mais de um momento de emergência da escrita escolar em objeto do discurso acadêmico, mas de um momento em que o discurso acadêmico sobre a escrita escolar encontra-se com seus limites estabelecidos, constituindo-se em formação discursiva cuja identidade se elabora em processos de delimitação recíproca para com discursos concorrentes (o oficial e o pedagógico, principalmente, em suas relações para o estabelecimento de um conjunto de leis e diretrizes para a Educação, bem como para a proposição de documentos subsidiários à implementação de proposições curriculares, como Guias e Propostas).

A sala de aula, como lugar do pedagógico, pode ser considerada, nas pesquisas produzidas então, como um lugar de intervenção projetada, intervenção que se realizaria por intermédio da atuação do professor. Há, neste momento histórico, um distanciamento entre professor e pesquisador, entre pesquisador e contexto de ensino: as intervenções da pesquisa não mais se realizam (como acontecia no momento histórico anterior) diretamente em contexto, tomado como campo em que se desenvolvia a investigação sob a responsabilidade direta do sujeito da investigação (que se movimentava ambivalentemente entre as posições de pesquisador e de professor) em suas decisões metodológicas (para a pesquisa e para a docência). Nas pesquisas realizadas na década de 90, as intervenções se projetam à distância, com base em contribuições de perspectivas teóricas específicas para a análise da escrita escolar: encontram-se então estudos de base estruturalista (PEREIRA, 1990); fundamentado nos estudos do texto (MOREIRA, 1990); de base semiótica (DUARTE, 1992); enunciativa (PERNAMBUCO, 1993); pragmática (PETRONI, 1994); e discursiva (AMARAL, 1996).

A circunscrição da fundamentação teórica, nas investigações realizadas no período, a uma única perspectiva, é outra característica diferenciadora do estado em que se encontrava o discurso acadêmico sobre 
escrita escolar, em relação às configurações anteriores, em que diferentes perspectivas teóricas concorriam para a constituição da escrita escolar em objeto de discurso. A apropriação de saberes para a fundamentação de propostas pedagógicas se realiza de modo a projetar o princípio de coerência que deveria estar subjacente à perspectiva teórica escolhida para subsidiar a proposição de elementos para o ensino de língua portuguesa. A coerência característica da base teórica adotada para a elaboração das propostas pedagógicas se projetaria, por sua vez, para o trabalho em sala de aula, solucionando problemas de ensino resultantes de falhas decorrentes das insuficiências dos saberes existentes em contexto de ensino ${ }^{2}$.

A constituição da escrita escolar em objeto de pesquisa parece se fazer, assim, com base na contraposição entre o princípio de coerência que seria próprio a determinada perspectiva teórica - adotada para fundamentar o trabalho de investigação e a proposição de possibilidades para o trabalho pedagógico - e a ausência da atuação desse princípio em contexto de ensino, o que produziria lacunas, que deveriam ser preenchidas; falhas, que deveriam ser reparadas; defasagens, que deveriam ser corrigidas.

Neste dispositivo que se constrói com a polarização entre contexto de pesquisa e contexto de ensino, associada à projeção de uma instância a que se atribui o estatuto de interlocutor virtual, o pesquisador se desloca de um polo a outro, e, dirigindo as considerações que realiza a um interlocutor projetado, que pode ocupar também a posição de objeto dessas considerações, constitui, nesse movimento, a escrita escolar em objeto de pesquisa.

Representativo do corpus relativo ao período histórico observado, o trabalho de Duarte (1992) se inicia apontando para os problemas de

\footnotetext{
${ }^{2}$ Esse princípio de coerência entre perspectiva teórica e proposta pedagógica é observado também, no período em questão, na própria elaboração de documentos oficiais de referência para o ensino: é o que se percebe na Proposta Curricular de Língua Portuguesa $-1^{\circ}$ grau (SÃO PAULO, 1987), cujo texto materializa a ordem própria à perspectiva teórica com base em que se produz esse documento (cf.: PIETRI, 2007b), fato diverso do que se observa para os Guias Curriculares da década de 70 (SÃO PAULO, 1975), em que não se encontram princípios de organização textual-discursiva controlados por uma perspectiva teórica específica, mas se observa a justaposição de perspectivas teóricas diversas.
} 
produção textual dos alunos brasileiros, principalmente no que se refere à modalidade escrita. Como referido, nesse momento, as pesquisas realizadas recorrem aos trabalhos acadêmicos antecedentes para apontar os problemas da escrita escolar e suas supostas causas. São referidos, na pesquisa em questão, os trabalhos de Savioli (1988), Rocco (1981) e Barros (1985) pelo que tratam sobre a suposta crise na linguagem e os modos como se relacionam com ela aqueles que de uma maneira ou de outra têm o ensino como uma de suas preocupações. Os problemas encontrados não seriam, segundo a autora, próprios às classes menos privilegiadas, mas se encontrariam em outros lugares da sociedade, mesmo os mais privilegiados, e estariam relacionados com o processo de escolarização formal. O lugar social em que localizada a escola, e a comunidade cultural que compõe os sujeitos que frequentam essa instituição deixam de se colocar, como se fazia no período anterior, como fatores decisivos para o ensino formal de língua portuguesa, dado que sustentariam as diferenças entre a língua do aluno e a língua da escola.

No mesmo sentido, a referência feita na década de 80 ao continuum que se poderia estabelecer entre oralidade e escrita, de modo a favorecer a produção textual do aluno, não mais é percebido neste momento seguinte. Segundo Duarte (1992), a escrita possuiria especificidades que fazem mais difícil sua aquisição, se comparada com a aquisição da modalidade oral. Aprender a ler e a escrever seria um processo mais tenso que aprender a falar dado o status que possuiria a escrita socialmente, o que diferenciaria as expectativas sociais sobre sua aquisição. Elemento também diferenciador do processo de aquisição das modalidades seria o referente ao contexto próprio a cada uma delas: o contexto da modalidade oral se caracterizaria por ser situacional, e não apenas verbal; o contexto próprio à modalidade escrita seria "simplesmente textual" (p. 22), e qualquer informação sobre o que se está lendo ou escrevendo deveria ser encontrada no próprio texto.

Seria preciso considerar ainda, segundo Duarte (1992), que a aquisição da oralidade se faz num "processo contínuo, informal e gradual", de maneira espontânea, com a colaboração de todos os circunstantes, ao passo que a aquisição da escrita se faria já segundo um processo de estranhamento, num sistema pronto e igual para todos os que frequentam a 
escola. A espontaneidade com que se aprenderia fora da escola seria interrompida, em seu interior, devido à organização de tempo e de espaço escolares, sujeitos a normas para a correção dos comportamentos.

O distanciamento entre escrita e oralidade é considerado em relação aos termos de Jakobson (1974) para as funções da linguagem: a criança adquiriria primeiramente e com mais facilidade os gêneros que privilegiariam a função emotiva, o que se mostra no fato de ela inicialmente tender a transcrever a fala em seu texto escrito; mais tarde apenas seria possível a emergência da função referencial, que demandaria um descentramento do leitor/escritor. Assim, oralidade e escrita estariam mais próximas quando do predomínio da função emotiva, e mais distantes quando do predomínio da função referencial. Essa relação explicaria então porque a produção de narrativas seria mais fácil que a produção de textos dissertativos.

A opção pela semiótica, então, para tratar de questões de ensino de escrita se justificaria pelo fato de sua abordagem da narrativa, que, como texto figurativo (em oposição, assim, ao dissertativo), estaria presente em sua diversidade, para todos os tempos e espaços sociais, para todos os grupos na sociedade, transcendendo qualquer juízo de valor. A potencialidade pedagógica que possuiria a narrativa não estaria sendo devidamente explorada na rotina das escolas públicas (p. 67), que poderiam utilizá-la para se aproximar, inclusive, dos alunos das classes mais pobres, que teriam com ela, a narrativa, uma relação, por princípio, prazerosa. Com base nas contribuições da semiótica, a autora propõe que se realize um percurso com a criança que vá do mais simples ao mais complexo, do concreto ao abstrato, do próximo ao distanciado, etc., possibilitando, assim, o desenvolvimento gradual das possibilidades discursivas da criança, para que ele se encaminhe dos discursos figurativos (como o narrativo), aos nãofigurativos (como o dissertativo). Faltariam, entretanto, ao professor, instrumentos eficazes de análise textual para lidar com o texto narrativo em contexto de ensino (p. 68).

Após revisar conceitos da Semiótica, a pesquisadora relata 0 processo de intervenção pedagógica realizado na $5^{\text {a }}$ série de uma escola 
pública da periferia de Diadema (SP). A intervenção ${ }^{3}$ durou um semestre, com atividades de leitura que visassem ao fornecimento de subsídios para as atividades de escrita. A semiótica ofereceria instrumentos para que os alunos dominassem as estruturas narrativas constitutivas do texto. Os alunos modificavam narrativas já dadas, ou narrativas escritas pelos colegas, ou, ainda, produziam narrativas próprias a partir de títulos fornecidos pela professora. As atividades de leitura e de escrita se faziam conjuntamente ao trabalho com a oralidade.

Os resultados obtidos, julgados interessantes, foram considerados em função das condições de trabalho encontradas em sala de aula (como a indisciplina dos alunos) e do fato de o projeto ter-se desenvolvido num tempo restrito, dadas as possibilidades da pesquisadora.

Consideradas as melhoras observadas nas produções textuais dos alunos, Duarte (1992) afirma, então, que seria "viável utilizar-se da teoria semiótica greimasiana para embasar um trabalho de produção de texto com alunos da escola básica, mesmo em escolas de periferia” (p. 173). A autora esclarece que não teve o objetivo de excluir a possibilidade de aplicação de outras teorias, mas tão somente de "testar as possibilidades do modelo".

Por fim, o último capítulo do trabalho apresenta uma proposta para prática de redação na escola: trata-se de retomada dos itens desenvolvidos no capítulo anterior, porém segundo estrutura de caráter instrucional, com a sequência dos pontos a serem desenvolvidos, acompanhados de comentários a respeito dos elementos teóricos, e, por vezes, de indicação da necessidade de formação do professor e das alterações nas rotinas de sala de aula.

Uma característica do período observado, como referido, é a projeção das perspectivas teóricas abordadas nas pesquisas em suas possibilidades de utilização no contexto escolar. As propostas pedagógicas

\footnotetext{
${ }^{3}$ Note-se, que, ainda que se realize parte da pesquisa em contexto de sala de aula, não há aproximação entre pesquisador e professor, como havia na década de 80: trata-se de intervenção, segundo experimento já construído com base em perspectiva teórica, e a ser realizado por um tempo restrito, como se afirma na sequência do texto. Destaque-se, também, que a primazia do teórico sobre o prático se evidencia na necessidade, como apontado pela pesquisadora, de se estabelecer metalinguagem adequada à teoria e à sua apropriação pelos alunos.
} 
se realizam, então, contrapostas às concepções e práticas que prevaleceriam em contexto de ensino, as quais seriam percebidas como responsáveis pelos problemas detectados nos textos escritos produzidos pelos alunos. O distanciamento entre professor e pesquisador é mesmo tematizado, referindo-se à falta de "diálogo entre Universidade e escola básica, pesquisador e professor da escola pública" (DUARTE, 1992).

A coerência teórica em contexto de pesquisa e a insuficiência teórica em contexto escolar representam os pontos de tensionamento para a constituição da escrita escolar em objeto de pesquisa no momento histórico observado, movimento que possui um terceiro elemento (externo) projetado na figura de uma interlocução virtual (considerando-se que as pesquisas realizadas possuem como horizonte de leitura o contexto acadêmico em que se produziram): os sujeitos em contexto de ensino. Esse elemento externo assume um estatuto ambíguo, no sentido do que poderia ser atribuído à terceira pessoa do discurso, que ocuparia, por vezes, a posição de referente, por vezes, a posição de pessoa do discurso (cf.: CERVONI, 1989). O estatuto ambíguo atribuído à terceira pessoa, nas pesquisas realizadas no período em observação, parece ser o que possibilita sua inserção na cena que se constrói, em que ocupa, então, a posição de objeto de que se fala, mas também a de sujeito a quem se fala - permanecendo sua possibilidade de manifestação apenas projetada.

A figura do professor, portanto, é o elemento em relação ao qual se referenciam as posições e os limites dos discursos em sua organização no espaço discursivo: a ambivalência de sua posição permite aos pesquisadores se movimentarem, e, em seu percurso, redefinirem os limites das formações discursivas, agenciando elementos teóricos e constituindo a escrita em objeto de discurso.

\section{CONSIDERAÇÕES FINAIS}

Em resumo, é possível apontar as seguintes características para cada um dos momentos históricos observados neste estudo: no período relativo à década de 70, o texto escrito escolar é considerado como sintoma das condições sociais e históricas em que se inseria a escola. O exterior da 
escola se representava, então, como o contexto da comunicação de massas e a indústria cultural.

$\mathrm{Na}$ década de 80, o texto escrito escolar é considerado como produto das condições de produção escolares, que se caracterizava por promover o encontro das diferenças linguísticas existentes entre os grupos sociais de origem dos alunos e a instituição escolar. O exterior da escola se constituiria como o lugar da cultura oral; a escola representaria o lugar da cultura escrita.

A década de 90 caracteriza-se pela circunscrição de um espaço escolar, contraposto ao espaço acadêmico. O texto escrito produzido na escola é visto, nas investigações então realizadas, como resultante de problemas encontrados no contexto escolar, marcado por lacunas teóricas que impediriam o desenvolvimento de práticas de ensino satisfatórias. A escola se constitui, então, como o destino das contribuições teóricas que as pesquisas acadêmicas poderiam oferecer para o ensino.

A constituição da escrita escolar em objeto de discurso, em cada momento histórico, se realiza com base na ambivalência projetada para um determinado par funcional. Na década de 70, a ênfase recai sobre o par aluno/aprendizagem, quando os problemas de redação eram percebidos como resultantes da não maturação cognitiva adequada do escrevente. Como visto, as causas desse desenvolvimento não suficiente são atribuídas aos efeitos provocados pela indústria cultural e pela comunicação de massas, contexto maior em que estaria inserido o aluno.

Na década de 80, a ênfase se coloca sobre a relação pesquisa/ensino, quando professor e pesquisador se aproximam, e, às vezes, se confundem, em seu trabalho de intervenção sobre o contexto escolar de modo a produzir saberes sobre a prática de ensino. Essa aproximação entre pesquisa e ensino se assenta na consideração da escola como espaço em que diferenças linguísticas são aproximadas, num processo tenso entre a variedade linguística do aluno e a variedade legitimada pela escola. O professor e o pesquisador se encontram (i.e.: se localizam e se aproximam) num contexto complexo, decorrente do acesso aos bancos escolares de classes sociais que até então não tinham direito à escolarização formal. Essa complexidade demanda a produção de saberes escolares e acadêmicos, num processo que se realiza então com a integração entre academia e escola. 
A década de 90 tem na relação entre o professor e a pesquisa o par funcional que sustenta o diálogo entre produção de saberes teóricos e desenvolvimento de práticas de ensino. Tem-se, nesse momento, já constituída uma memória para o tratamento da escrita escolar enquanto objeto de investigações linguísticas. O professor é projetado, então, como o destinatário dos saberes produzidos academicamente com base em recursos teóricos específicos. Essa projeção se faz tanto na tematização do trabalho e da formação docente, quanto na perspectiva de que os resultados das pesquisas informariam a prática do professor em sala de aula. Academia e escola compõem, assim, contextos diversos, e a transposição de saberes da primeira para a segunda teria como objetivo diminuir as diferenças existentes entre elas.

No período observado, portanto, estabeleceram-se e alteraram-se índices enunciativos para a referência de pessoa, tempo e espaço com base no (re)posicionamento dos limites contextuais entre o intra e o extraescolar. Os limites entre os discursos em concorrência se estabeleceram, assim, em decorrência do trabalho realizado pelos sujeitos em seus movimentos entre os índices enunciativos que referenciaram o percurso entre pesquisa e ensino em cada um dos momentos históricos observados. As diferentes posições ocupadas pelos pesquisadores em relação a esses índices possibilitaram a apropriação de saberes para a constituição da escrita escolar em objeto de discurso.

Nesse sentido, não se considera que o processo observado tenha se caracterizado por ser estruturalmente sobredeterminado, ou resultante de acontecimentos recobertos pelo discurso, mas produto do trabalho histórico de sujeitos situados: desse trabalho, novos objetos se produziram, uma memória se constituiu. A presente pesquisa encontrou marcas dessa elaboração desde a construção de novas possibilidades de dizer, quando poucos recursos havia para que se pudesse constituir em objeto de pesquisa ou de ensino, em bases linguísticas, a escrita escolar. 


\section{REFERÊNCIAS}

BRASIL. Parâmetros Curriculares nacionais: 1a a 4a Séries do Ensino

Fundamental. Secretaria de Educação Fundamental. Brasília: MEC/SEF, 1997. . Parâmetros curriculares nacionais: terceiro e quarto ciclos do ensino fundamental: língua portuguesa/Secretaria de Educação Fundamental. Brasília: $\mathrm{MEC} / \mathrm{SEF}, 1998$.

CERVONI, J. A enunciação. São Paulo: Ática, 1989.

HALLIDAY, M. A. K.; HASAN, R. Cohesion in spoken and written English. London: Longman's English Language Series, 1973.

JAKOBSON, R. Lingüística e Comunicação. 7. ed. São Paulo: Cultrix, 1974.

KATO, M. No mundo da escrita. Uma perspectiva psicolingüística. 2. ed. São Paulo: Ática, 1986.

MARCUSCHI, L. A. Análise da conversação. São Paulo: Ática, 1986.

KOCH, I. G. V. Argumentação e linguagem. 2. ed. São Paulo: Cortez, 1987.

LABOV, W.; WALETZKY, J. Narrative analysis: oral versions of personal experience. In: HELM, J. Essays on the verbal and visual arts. Washington: University of Washington Press, 1967. p. 12-44

MAINGUENEAU, D. Novas tendências em Análise do Discurso. Tradução Freda Indursky. Campinas: Pontes/Editora da Unicamp, 1997.

. Gênese dos discursos. Trad. Sírio Possenti. Curitiba: Criar Edições, 2005.

ORLANDI, E. P. A linguagem e seu funcionamento. 2. ed. São Paulo: Brasiliense, 1987.

PIETRI, E. A constituição da escrita escolar em objeto de análise dos estudos lingüísticos. Trabalhos em Linguística Aplicada, Campinas, v. 46, p. 283-297, 2007a.

. Circulação de saberes e mediação institucional em documentos oficiais: análise de uma proposta curricular para o ensino de língua portuguesa. Currículo sem Fronteiras, v. 7, p. 263-283, $2007 \mathrm{~b}$.

. Sobre a constituição da disciplina curricular de língua portuguesa. Revista Brasileira de Educação, Rio de Janeiro, v. 15, n. 43, p. 70-83, 2010.

SÃO PAULO (Estado) Guias Curriculares para o ensino de $1^{\circ}$ grau. São Paulo, Secretaria da Educação, Cerhupe, 1975.

. Proposta Curricular para o Ensino de Língua Portuguesa: $1^{\circ}$ grau. São Paulo: Secretaria Estadual de Educação/CENP, 1987. 
SILVA, T. R. N.; ARELARO, L. R. G., Orientações legais na área de currículo, nas esferas federal e estadual a partir da Lei 5.692/71. Cadernos Cedes, Campinas, v. 1, n. 13 , p. 26-44, 1985.

SOARES, M. Português na escola: história de uma disciplina curricular. In: BAGNO, M. (Org.). Linguística da norma. São Paulo: Loyola, 2002. p. 155-177 VIANNA, H. M. Redação e medida da expressão escrita: algumas contribuições da pesquisa educacional. Cadernos de Pesquisa, São Paulo, n. 16, p. 41-47, 1976.

\section{CORPUS}

ALMEIDA, M. A. C. Coesão textual da linguagem dos pré-adolescentes. 1980. Dissertação (Mestrado em Linguística)-Instituto de Estudos da Linguagem, Universidade Estadual de Campinas, Campinas, 1980.

AMARAL, N. F. G. Clichês em redações de vestibular: estratégia discursiva. 1996. Dissertação (Mestrado em Linguística)-Instituto de Estudos da Linguagem, Universidade Estadual de Campinas, Campinas, 1996.

BASTOS, L. K. X. Coesão e coerência em narrativas escolares escritas. 1984. Dissertação (Mestrado em Linguística)-Instituto de Estudos da Linguagem, Universidade Estadual de Campinas, Campinas, 1984.

BASTOS, D. R. Análise do desempenho de adolescentes em teste gramatical e de sua transferência para a linguagem escrita. 1986, 115f. Dissertação (Mestrado em Semiótica e Linguística Geral)-Faculdade de Filosofia, Letras, Ciências Humanas, Universidade de São Paulo, São Paulo, 1986.

DIAS, E. G. S. Incapacidade de expressão ou adaptação a novos padrões? 1977.

Dissertação (Mestrado em Educação)-Faculdade de Educação, Universidade Estadual de Campinas, Campinas, 1977.

DUARTE, J. M. Produção escrita de alunos da escola pública: a possível contribuição da semiótica. 1992, 221f. Tese (Doutorado em Semiótica e Linguística Geral)-Faculdade de Filosofia, Letras, Ciências Humanas, Universidade de São Paulo, São Paulo, 1992.

GALLO, S. L. O ensino da língua escrita X o ensino do discurso escrito. 1989.

Dissertação (Mestrado em Linguística)-Instituto de Estudos da Linguagem, Universidade Estadual de Campinas, Campinas, 1989.

HILGERT, J. G. A ilusão da escrita - uma análise semântica de redações de vestibular. 1978. Dissertação (Mestrado em Semiótica e Linguística Geral)Faculdade de Filosofia, Letras, Ciências Humanas, Universidade de São Paulo, São Paulo, 1978. 
MESERANI, S. C. A redação (relação) escolar. 1980, 290f. Dissertação (Mestrado em Comunicação e Semiótica)-Pontifícia Universidade Católica de São Paulo, São Paulo, 1980.

MOREIRA, M. M. A progressão temática na redação escolar. 1991, $137 \mathrm{f}$. Dissertação (Mestrado em Linguística Aplicada)-Instituto de Estudos da Linguagem, Universidade Estadual de Campinas, Campinas, 1991.

MOYSÉS, S. M. A. Criatividade verbal e adjetivação em redação: um estudo experimental com a técnica de cloze. 1976. Tese (Doutorado em Semiótica e Linguística Geral) - Faculdade de Filosofia, Letras, Ciências Humanas, Universidade de São Paulo, São Paulo, 1976.

PEREIRA, R. F. Contribuição para o estudo de problemas de redação. 1990, $231 \mathrm{f}$. Tese (Doutorado em Letras)-Faculdade de Ciências e Letras, Universidade Estadual Paulista, Campus de Assis, 1990.

PERNAMBUCO, J. A redação escolar: análise dos efeitos da escolaridade. 1993, 233f. Tese (Doutorado em Educação)-Faculdade de Educação, Universidade de São Paulo, São Paulo, 1993.

PETRONI, M. R. A organização do texto escrito por alunos do $1^{\circ}$ grau. 1994. Dissertação (Mestrado em Linguística)-Instituto de Estudos da Linguagem, Universidade Estadual de Campinas, Campinas, 1994.

ROCCO, M. T. F. Texto e Discurso: uma caracterização da linguagem escrita de candidatos a vestibulares. 1981, 299f. Tese (Doutorado em Educação)- Faculdade de Educação, Universidade de São Paulo, São Paulo, 1981.

SATO, N. O aluno e a produção do texto escrito: Travessias. Uma análise de redações de alunos do $2^{\circ}$ grau. 1989. Dissertação (Mestrado em Educação)Faculdade de Educação, Universidade de São Paulo, São Paulo, 1989.

SAVIOLI, F. R. O ensino da leitura - um projeto gradual e ininterrupto. 1988, 343f. Tese (Doutorado em Semiótica e Linguística Geral)-Faculdade de Filosofia, Letras, Ciências Humanas, Universidade de São Paulo, 1988.

\section{Recebido em: 04/06/13. Aprovado em: 30/11/13.}

Title: The limits of context: the constitution of school writing as object of linguistics research

Author: Émerson de Pietri

Abstract: In this paper, we present some results of an investigation in which the establishment of school writing as object of linguistics research was observed. The corpus of analysis was composed of research reports produced in the last three decades of the twentieth century, in Brazilian Universities' postgraduate programs. The 
analysis was developed in order to observe the constitution of a specific discursive space. The investigation revealed different ways in which school context was defined in relation to extra school context elements. Based on the (re)positioning of contextual boundaries between intra and extra school limits, enunciative indexes were allocated, changing the modes of reference to person, time and space. The positions occupied by the researchers, regarding these indexes allowed the appropriation of the theoretical knowledge used to configure school writing as an object of discourse.

Keywords: Interdiscourse. Academic Research. School Writing.

Título: Los límites del contexto: la constitución de la escritura escolar en objeto de los estudios lingüísticos

Autor: Émerson de Pietri

Resumen: En el presente trabajo, se presentan resultados de investigación en que la se observó el proceso histórico de constitución de la escritura escolar en objeto de investigaciones académicas. Se analizaron informes de investigaciones desarrollados en programas de pos graduación en las tres últimas décadas del siglo XX. Se buscó comprender el proceso en cuestión como constitución de un espacio discursivo específico. La investigación puso en evidencia el proceso de redefinición de los modos como representado el contexto en que se elaboraría el texto escrito escolar. Con base en el (re)posicionamiento de los límites contextuales entre el intra y el extraescolar se establecieron y se alteraron indices enunciativos para la referencia de persona, tiempo $y$ espacio. Las posiciones ocupadas por los investigadores en relación a esos índices posibilitaron la apropiación de saberes para la constitución de la escritura escolar en objeto de discurso.

Palabras-clave: Interdiscurso. Investigación Académica. Escritura Escolar. 